\title{
ABPAR and the Needs of Patients with Amyloidosis in Brazil
}

\author{
Liana Cláudia Uriarte Ferronato ${ }^{(-)}$ \\ Associação Brasileira de Paramiloidose (ABPAR), São Paulo, SP - Brazil
}

The Brazilian Paramyloidosis Association (ABPAR) ${ }^{1}$ was founded on November 17, 1989 at the in the Convention Room of Hotel Rio Copa, in the city of Rio de Janeiro. In December of that year, it became a legal entity following registration at the notary's office and publication in the Brazilian Official Gazette.

Starting then, members began the fight against the countless obstacles in the dissemination and prevention of familial amyloidotic polyneuropathy, also known as hereditary transthyretin amyloidosis. Due to lack of information, the Brazilian population, all too often, would not seek assistance and, when people did so, public agencies would not provide it, refusing to invest material and funds in this serious and fatal health problem.

In addition to monitoring medical-scientific research in the search for solutions for people who carry hereditary transthyretin amyloidosis, the ABPAR also understands the great importance of an educational focus, offering lectures and regional events that include patients, family members, and doctors from the diverse areas related to providing care for this disease.

The ABPAR, through the functions highlighted in its Mission Statement, seeks an alliance with science to improve the relationship of patients and family members who deal with this reality, in order to promote greater awareness and acceptance of the disease and to increase the capacity to react in the search for treatment and quality of life.

When Glaide Mara's father passed away, in March 2008, the association went on hiatus until the year 2011.

\section{Revival of the ABPAR in 2011}

The first reunion took place at Glaide Mara's residence, on May 14, 2011, and a commitment was made to start promoting the association and aggregating new members. Several meetings were scheduled, raising contributions to begin with the revival of the association.

On September 18, 2011, the fifth meeting took place, according to the publication in the newspaper O Dia, the

\section{Keywords}

Amyloidosis; Hereditary Amyloidosis; Hereditary Amyloidosis TTP; Hereditary Amyloidosis associated with TTR - PAF - CAF; Amyloidotic Cardiomyopathy; Amyloidotic Neuropathy; ABPAR; Rare Diseases.

Mailing Address: Liana Cláudia Uriarte Ferronato •

Associação Brasileira de Paramiloidose

Av. Paulista, 1439, cj 12. Postal Code: 01311-926, São Paulo, SP - Brazil.

Email: liana@abpar.org.br

Manuscript received September 08, 2021, revised manuscript September 24, 2021, accepted September 24, 2021.

DOI: https://doi.org/10.36660/abchf.20210018 new board members of the ABPAR were elected, maintaining Roberto Beltrami as president, and Glaide was elected vice president. The bylaws of the ABPAR were registered in accordance with the new civil code.

Subsequently, faced with a situation where all proposals vanished and the members became increasingly sick, meetings became more and more difficult; judicial barriers accumulated, and the group lost its strength. Once more, the ABPAR went on hiatus.

In 2014, a new group of patients got together, following conversations on the theme of amyloidosis in social networks, and they decided, once again, to revive the association, with Fabio Almeida as president until September 2020. In September 2020, I was elected to head the current management.

To explain a little about hereditary transthyretin amyloidosis, we can say that Brazil is an endemic country due to its history of colonization; for this reason, the vast majority of patients have the Portuguese VAL50MET and African ILE142 genetic mutation variants, in addition to many others from other peoples, with diverse origins, who came to this country. Hereditary transthyretin amyloidosis may present cardiac, neuropathic, or mixed phenotypes, depending on the mutation. Due to this diversity, the age of onset of the disease may vary substantially, starting at 20 years. Life expectancy after the first symptoms is 10 years for those with the untreated neuropathy phenotype and 5 years for those with the cardiac phenotype, for whom there is still no therapeutic option available through the Brazilian Unified Health System.

Today, I have taken up this commitment with the goal of maintaining the institution and, above all, continuing the work of spreading awareness about the disease, which is essential so that we will have access to treatments that already exist, but which still require approval and distribution in Brazil's national health system.

The work of the ABPAR is also aimed at seeking information to guide patients and their families regarding where they can seek specialized care and which treatments are available, in addition to attempts to create more referral centers that can facilitate patient access to locations that are closer to their homes.

Furthermore, ABPAR is mobilizing so that new treatments will be approved by the responsible organs, by means of reunions involving specialist doctors and patients, forwarding official communications and letters to government representatives who work for the cause and to the organs that make decisions regarding the adaptation and distribution of these new treatments, in addition to campaigns on social networks, awareness movements, and petitions. We currently have an open petition, which already has more than 35,000 signatures, asking for the pricing and inclusion of two newer medications for the most serious stages of the disease, the Inoteresen and the Patisiran. During the conference period of this article, we had information from the Ministry of Health 


\section{Editorial}

that this issue was resolved and both drugs were priced and approved as category 1 , which refers to innovative treatment.

In order to meet the needs of patients with transthyretin amyloidosis in Brazil, our work is thus essentially focused on seeking and forming support networks that offer multidisciplinary diagnosis and treatment, because, in both the neuropathic and cardiac forms, the disease affects several organs. This work is very difficult, given that all of the therapeutic forms have yet to be made available to everyone, be it due to the fact that they have not yet been offered through the Brazilian Unified Health System, due to very high costs that make them impossible to purchase privately, or due to difficulty in finding doctors who are familiar with the disease and who know what to do for patients.

Today, our greatest challenge lies precisely in these three situations: early diagnosis, creation of more referral centers, and access to treatments for all forms and stages of transthyretin amyloidosis. This is not an easy task, but it is my understanding that we all have the right to life, and it is our duty to seek treatment, given that it does exist.

\section{Reference}

1. Associação Brasileira de Paramiloidose [Internet]. São Paulo: ABPAR; c2021 [cited 2021 Sep 26]. Available from: www.abpar.org.br. 